\title{
Correlation between KRAS, NRAS and BRAF mutations and tumor localizations in patients with primary and metastatic colorectal cancer
}

\author{
Aleksandra Bożyk ${ }^{1}$, Paweł Krawczyk ${ }^{1}$, Katarzyna Reszka², Kinga Krukowska², Agnieszka Kolak ${ }^{3}$, \\ Sławomir Mańdziuk ${ }^{3}$, Kamila Wojas-Krawczyk ${ }^{1}$, Rodryg Ramlau ${ }^{4}$, Janusz Milanowski ${ }^{1}$
}

\begin{abstract}
${ }^{1}$ Department of Pneumonology, Oncology and Allergology, Medical University of Lublin, Lublin, Poland

2Institute of Genetics and Immunology GENIM LLC, Lublin, Poland

${ }^{3}$ Department of Oncology and Chemotherapy, Medical University of Lublin, Lublin, Poland

${ }^{4}$ Department of Oncology, Medical University of Poznan, Poznan, Poland
\end{abstract}

Submitted: 12 December 2018; Accepted: 6 May 2019

Online publication: 24 March 2021

Arch Med Sci 2022; 18 (5): 1221-1230

DOI: https://doi.org/10.5114/aoms/109170

Copyright (c) 2021 Termedia \& Banach

\begin{abstract}
Introduction: Detection of abnormalities in the KRAS, NRAS and BRAF genes is extremely important for proper qualification of colorectal cancer (CRC) patients for therapy with anti-EGFR (epidermal growth factor receptor) monoclonal antibodies. However, data about prevalence of mutations in these genes, in different localizations of CRC tumors, are limited.

Material and methods: We examined the frequency of mutations in the KRAS, NRAS and BRAF genes in 500 Caucasian CRC patients (200 women and 300 men, median age 66 years). DNA was isolated from formalin-fixed, paraffin-embedded (FFPE) tissues using a Qiagen QIAamp DNA FFPE-kit. Analysis of mutations was carried out using the KRAS/BRAF, NRAS and BRAF Mutation Analysis Kit for Real-Time PCR (EntroGen) with the Cobas 480 realtime PCR apparatus (Roche Diagnostics).

Results: KRAS mutations were detected in 190 (38\%) patients, NRAS mutations in 20 (4\%) patients, and BRAF mutations in 24 (4.8\%) patients. There were no associations between age of CRC patients and frequency of KRAS, NRAS and BRAF gene mutations. These mutations were significantly more often diagnosed in women $(55.5 \%)$ than in men $(41 \%, p<0.005)$. Tumors of the rectum and sigmoideum were the most often observed in both groups of CRC patients - with and without KRAS, NRAS and BRAF gene mutations. However, transverse colon, ascending colon and cecum cancers were the most often affected by mutations.

Conclusions: Our study showed that the occurrence of mutations in the KRAS, NRAS and BRAF genes is not accidental and depends on the location of CRC tumors.
\end{abstract}

Key words: KRAS, NRAS, BRAF, colorectal cancer.

\section{Introduction}

According to the American Cancer Society, there were over 135,000 new cases of colorectal cancer (CRC) $(95,520$ colon cancers and 39,910 rectal cancers) in 2017 in the United States. Due to the large number of new cases, colorectal cancer was in the third place among the cancerous

\author{
Corresponding author: \\ Aleksandra Bożyk MSc \\ Department of \\ Pneumonology, Oncology \\ and Allergology \\ Medical University of Lublin \\ 8 Jaczewskiego St \\ 20-950 Lublin, Poland \\ E-mail: bozyk.ola@gmail.com
}


causes of deaths in men and women, which resulted in more than 50,000 deaths for this reason in the US in 2017, and about 655,000 worldwide. The risk of this type of cancer is slightly higher in men than in women [1-3].

Many aspects are mentioned among the causes of development of CRC. First of all, scientists have acknowledged that the main factor which increases the risk of the disease is inheritance of mutations from first-degree relatives. Almost 30\% of patients have at least one relative in the family who suffers from CRC [2]. The second factor that predisposes to CRC is familial adenomatous polyposis (FAP), which appears in around $1 \%$ of all CRC cases. Another disease which can predispose to CRC is chronic inflammatory bowel disease, as known as Crohn disease and ulcerative colitis. Authors, among risk factors, also mention diet and lifestyle, type 2 diabetes, cigarette smoking, alcohol abuse, obesity, diet low in fiber, and an excess of consumed fats, carbohydrates as well as red and processed meat. Physical activity and long-term treatment with low doses of aspirin may have preventive value in the development of CRC. These factors have different influence on particular parts of the colon, sigmoideum and rectum [1, 2].

The RAS and RAF family proteins mediate signaling of growth factor receptors via the PI3K-AKTmTOR and RAS-RAF-MEK-ERK pathways, thereby participating in cell survival and proliferation [4]. Excessive activity of these signaling pathways is often found in various cancers. It is caused mainly by mutations in RAS and BRAF genes. Based on the deficiency of DNA repair and influence of carcinogens, these oncogenes are often mutated in CRC patients. Right-sided colon cancer is characteristic for women and probably shows microsatellite instability as well as BRAF mutations. Left-sided colon cancer is more common in men and shows chromosomal instability as well as KRAS mutations. Detection of abnormalities in the KRAS, NRAS and $B R A F$ genes is extremely important for proper qualification of patients for panitumumab and cetuximab therapy, which have been authorized by the Food and Drug Administration (FDA) and European Medicines Agency (EMA) on the basis of several clinical trials, including PRIME (panitumumab) and CRYSTAL (cetuximab) studies [5-11].

In our study, we examined the frequency of mutations in the KRAS, NRAS and BRAF genes in a large group of Caucasian CRC patients. The molecular tests were performed during the routine diagnostic process in qualification of CRC patients for first line chemotherapy with anti-EGFR (epidermal growth factor receptor) antibodies. For the first time, we examined the relationship between the exact location of CRC and the presence of particular mutations.

\section{Material and methods}

The study group included 500 patients (200 women and 300 men) with CRC including cancers in the small intestine (ICD-10: C17), colon (ICD-10: C18), rectosigmoid flexure (ICD-10: C19), rectum (ICD-10: C20) and anus (ICD-10: C21). The median age for men and women was the same: 66 years. 447 patients had locally advanced disease, while 53 patients had metastases at the time of diagnosis (with available material from the metastases). Patients were characterized in terms of age, gender and tumor localization. In the studied population, rectal and sigmoid cancers were the most common (61\% of all CRC patients). Detailed characteristics of our group are presented in Table I.

DNA was isolated from formalin-fixed, paraffin-embedded (FFPE) tissues using the Qiagen QIAamp DNA FFPE-kit with the CE-IVD certificate. Tissue was collected and mutations were searched at the time of the diagnosis of colon and rectum cancer. The DNA was isolated from a paraffin block containing at least $50 \%$ of tumor cells. The percentage and presence of cancer cells were confirmed in the pathomorphological examination. FFPE samples were collected in 2012-2018. Analysis of mutations in the KRAS, NRAS and $B R A F$ genes was carried out using three kits of the KRAS/BRAF, NRAS and BRAF Mutation Analysis Kit for Real-Time PCR (EntroGen, CE-IVD), on Cobas 480 real-time PCR apparatus (Roche Diagnostics). The tests examined the most common mutations in codons 12,13, 59, 61, 117 and 146 in KRAS and NRAS genes, as well as in codon 600 of the $B R A F$ gene. The tests can detect a mutation load of less than $1 \%$. This sensitivity greatly depends on the extent of fragmentation and quality of the isolated DNA.

No attempt was made to find mutations in whole blood due to the availability of only FFPE tissues.

\section{Statistical analysis}

Statistical analysis was performed using the $\chi^{2}$ test to determine the relationship between different tumor localization and the occurrence of mutations. Results were statistically significant when the $p$ value was below 0.05 .

The study was approved by the Local Ethical Committee of the Medical University of Lublin (no. KE-0254/218/2015).

\section{Results}

\section{Frequency of $K R A S, N R A S$ and $B R A F$ mutations in colorectal cancer}

KRAS mutations were detected in 190 (38\%) patients, NRAS mutations in 20 (4\%) patients, 


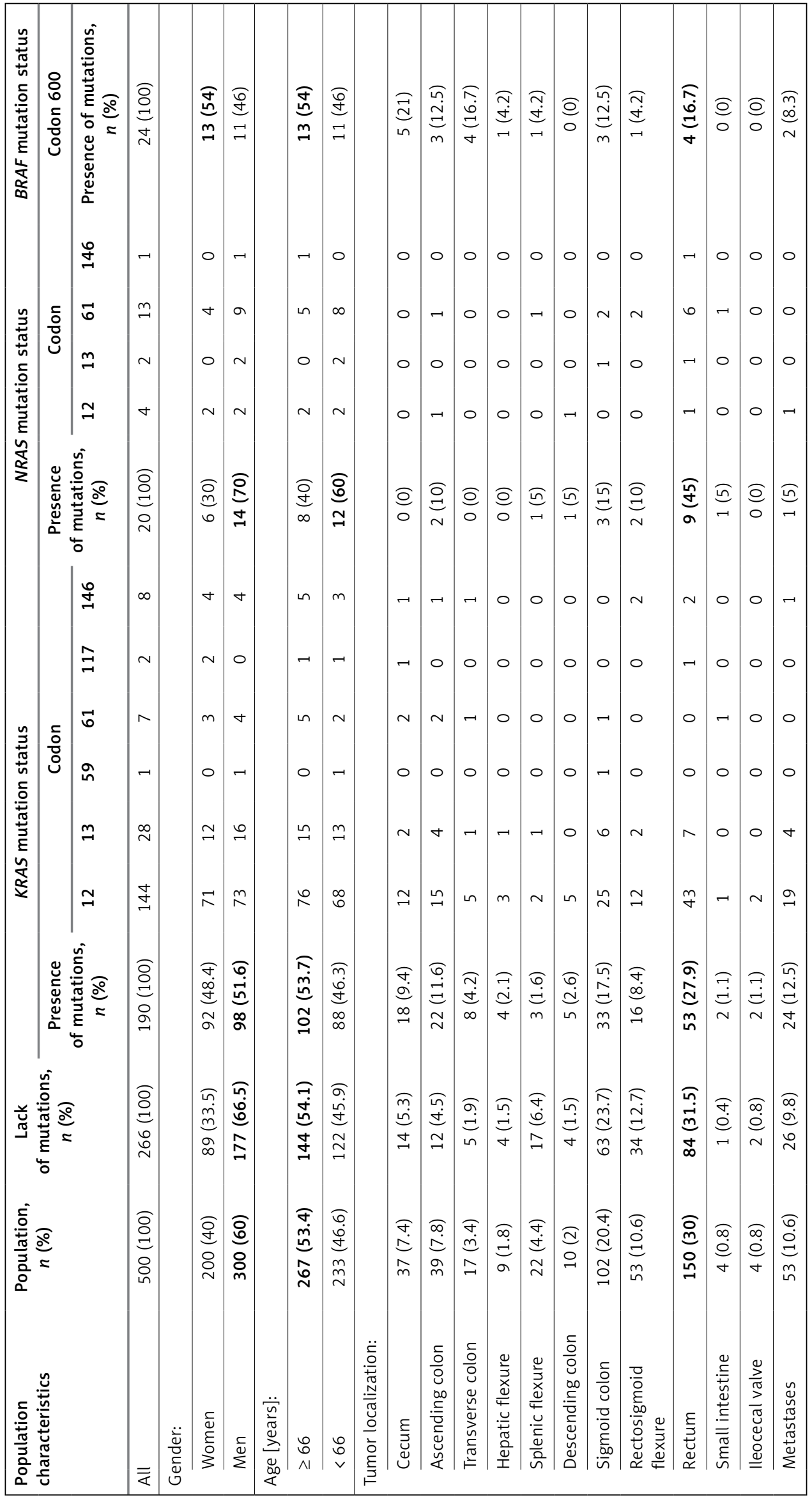




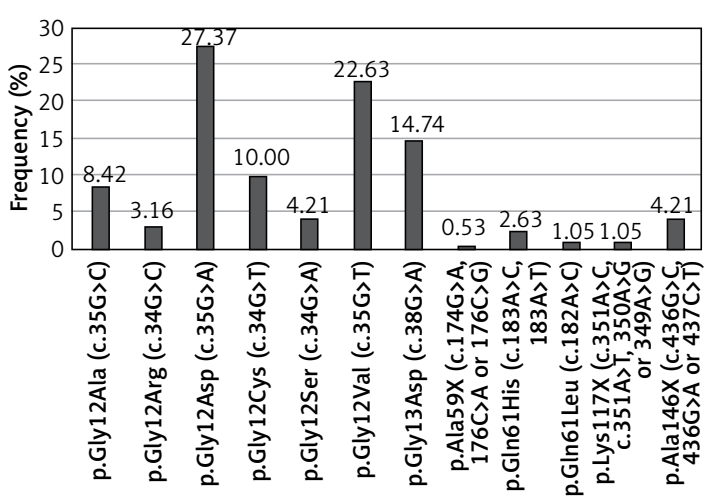

Figure 1. Frequency of mutations in particular codons of the KRAS gene

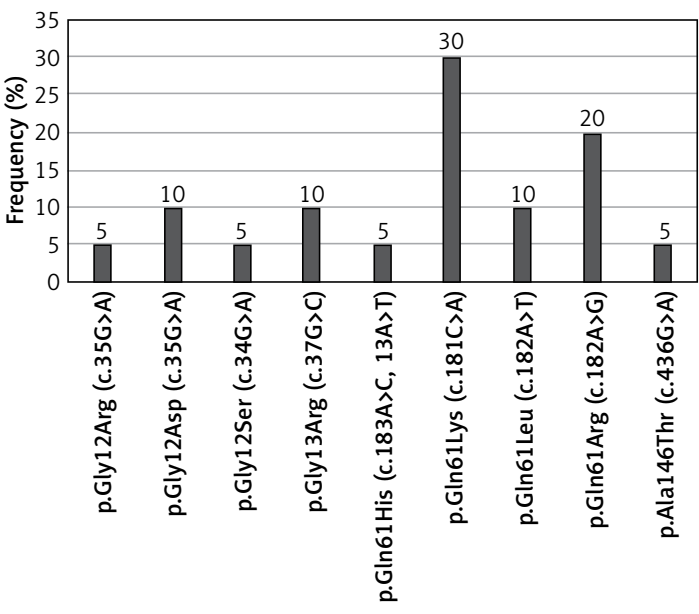

Figure 2. Frequency of mutations in particular codons of the NRAS gene

and BRAF mutations in $24(4.8 \%)$ patients. The most common substitution in the KRAS gene was p.Gly12Asp (27.37\% of all KRAS mutations; $52 / 190)$. $90.53 \%$ of KRAS mutations occurred in codon 12 or 13 (Figure 1). The most common substitution in the NRAS gene was Gln61Lys (30\% of all NRAS mutations; $6 / 20$ ). $65 \%$ of NRAS mutations were found in codon 61 (Figure 2). Among all $B R A F$ mutations, only Val600Glu was found.

\section{Association between age, gender, tumor localization and mutation status}

There were no associations between age of CRC patients and frequency of KRAS, NRAS and $B R A F$ gene mutations. These mutations were sig nificantly more often diagnosed in women $(55.5 \%$ of female patients; $111 / 200)$ than in men ( $41 \%$ of male patients; $123 / 300, p<0.005)$. The frequency of KRAS mutations and BRAF mutation was significantly higher in female than in male patients $\left(\chi^{2}=8.266, p=0.0044\right.$ and $\chi^{2}=4.14, p=0.042$, respectively), while the frequency of NRAS mutations was similar in both sexes $\left(\chi^{2}=0.1, p=0.75\right)$ (Tables I and II).
Rectal and sigmoid cancers were the most often diagnosed tumors in both groups of patients: with and without KRAS, NRAS or BRAF gene mutations (Table I). However, only $28 \%$ of patients with KRAS mutations (53/190) and up to $45 \%$ of patients with NRAS mutation (9/20) had rectal cancer. The most common tumor localization in patients with BRAF mutations was the cecum ( $21 \%$ of patients with this mutation; 5/24) (Table I). Mutations were most often found in tumors of the transverse coIon $(70.6 \%$ of all patients with transverse colon cancer, $12 / 17, p<0.05$ in comparison to other CRC localizations) and the ascending colon $(73 \%$ of all patients with ascending colon cancer, $27 / 39$, $p<0.005$ in comparison to other CRC localizations) as well as in cecum cancer $(62.2 \%$ of patients with cecum cancer, 23/37, $p=0.0516$ in comparison to other CRC localizations). Patients with cancers of the sigmoideum (38.2\% of all sigmoid cancer, $39 / 102, p=0.052$ in comparison to other CRC localizations) and splenic flexure $(22.7 \%$ of all splenic flexure cancer, 5/22, $p<0.05$ in comparison to other CRC localizations) had mutations confirmed the least frequently. Mutations were significantly more often found in patients with colon cancer including cancer of the cecum $(56.7 \%$ of mutated tumors) than in patients with sigmoid and rectal cancers $(42.6 \%$ of mutated tumors, $p=0.002$, $\chi^{2}=9.57$ ) (Table II). The mutation significantly more frequently occurred on the right side of the large intestine (65\% of this localizations of tumor, $63 / 97)$ than on the left side of the large intestine (40.8\% of this localization of tumor, $141 / 366)$. The incidence of KRAS and BRAF genes varied depending on the CRC localization in the right or left parts of the large intestine. In contrast, mutations in the NRAS gene occurred at a similar frequency in these two CRC localizations (Table III).

The differences in the occurrence of individual CRC in men and women with and without mutations in the KRAS, NRAS and BRAF genes were not significant. However, mutations in the KRAS gene in the small intestine and in the ileocecal valve were found only in female patients (Figure 3). Male patients with NRAS mutations suffered primarily from rectal cancer $(57.1 \%$ of all men with NRAS mutations) and cancer of the rectosigmoid flexure (14.3\% of all men with NRAS mutations). Single cases of sigmoid, ascending colon and small intestine cancers were found in men with NRAS mutations, whereas $50 \%$ of female patients with NRAS mutations suffered from colon cancer. Two cases of sigmoid and 1 case of rectal cancer were found in female patients with NRAS mutations. $45.5 \%$ of men and only $23.1 \%$ of women with $B R A F$ mutation had rectal or sigmoid cancers, whereas colon $38.5 \%$ of all women with $B R A F$ mutations) and cecum $(23.1 \%$ of all women with 
Table II. Relationship between occurrence of mutations in the KRAS, NRAS and BRAF genes and sex, age, and tumor localization in colorectal cancer (CRC) patients

\begin{tabular}{|c|c|c|c|c|c|}
\hline Patient characteristics & $n$ & $\%$ & Mutation status & $n$ & $\%$ \\
\hline \multirow[t]{2}{*}{ All } & \multirow[t]{2}{*}{500} & \multirow[t]{2}{*}{100} & Lack of mutation & 266 & 53.2 \\
\hline & & & Presence of mutation & 234 & 46.8 \\
\hline \multicolumn{6}{|l|}{ Age [years]: } \\
\hline \multirow[t]{2}{*}{$\geq 66$} & \multirow[t]{2}{*}{267} & \multirow[t]{2}{*}{53.4} & Lack of mutation & 144 & 53.9 \\
\hline & & & Presence of mutation & 123 & 46.1 \\
\hline \multirow[t]{2}{*}{$<66$} & \multirow[t]{2}{*}{233} & \multirow[t]{2}{*}{46.6} & Lack of mutation & 122 & 52.4 \\
\hline & & & Presence of mutation & 111 & 47.6 \\
\hline \multicolumn{3}{|l|}{$p, \chi^{2}$} & \multicolumn{2}{|c|}{$0.72,0.24$} & \\
\hline \multicolumn{6}{|l|}{ Gender: } \\
\hline \multirow[t]{2}{*}{ Women } & \multirow[t]{2}{*}{200} & \multirow[t]{2}{*}{40} & Lack of mutation & 89 & 44.5 \\
\hline & & & Presence of mutation & 111 & 55.5 \\
\hline \multirow[t]{2}{*}{ Men } & \multirow[t]{2}{*}{300} & \multirow[t]{2}{*}{60} & Lack of mutation & 177 & 59.0 \\
\hline & & & Presence of mutation & 123 & 41.0 \\
\hline \multicolumn{3}{|l|}{$p, \chi^{2}$} & \multicolumn{3}{|c|}{$0.00145,10.134$} \\
\hline \multicolumn{6}{|l|}{ Tumor localization: } \\
\hline \multirow[t]{2}{*}{ Small intestine } & 4 & 0.8 & Lack of mutation & 1 & 25.00 \\
\hline & & & Presence of mutation & 3 & 75.00 \\
\hline Other localizations & 496 & 99.2 & Lack of mutation & 265 & 53.43 \\
\hline & & & Presence of mutation & 231 & 46.57 \\
\hline$p, \chi^{2}$ & & & 0.256 & & \\
\hline Ileocecal valve & 4 & 0.8 & Lack of mutation & 2 & 50.00 \\
\hline & & & Presence of mutation & 2 & 50.00 \\
\hline Other localizations & 496 & 99.2 & Lack of mutation & 264 & 53.23 \\
\hline & & & Presence of mutation & 232 & 46.77 \\
\hline$p, \chi^{2}$ & & & 0.896 & & \\
\hline Cecum & 37 & 7.4 & Lack of mutation & 14 & 37.84 \\
\hline & & & Presence of mutation & 23 & 62.16 \\
\hline Other & 463 & 92.6 & Lack of mutation & 252 & 54.43 \\
\hline localizations & & & Presence of mutation & 211 & 45.57 \\
\hline$p, \chi^{2}$ & & & 0.051 & & \\
\hline Ascending colon & 39 & 7.8 & Lack of mutation & 12 & 30.77 \\
\hline & & & Presence of mutation & 27 & 69.23 \\
\hline Other localizations & 461 & 92.2 & Lack of mutation & 254 & 55.10 \\
\hline & & & Presence of mutation & 207 & 44.90 \\
\hline$p, \chi^{2}$ & & & 0.003 & & \\
\hline Hepatic flexure & 9 & 1.80 & Lack of mutation & 4 & 44.44 \\
\hline & & & Presence of mutation & 5 & 55.56 \\
\hline Other localizations & 491 & 98.2 & Lack of mutation & 262 & 53.36 \\
\hline & & & Presence of mutation & 229 & 46.64 \\
\hline$p, \chi^{2}$ & & & 0.595 & & \\
\hline Transverse colon & 17 & 3.40 & Lack of mutation & 5 & 29.41 \\
\hline & & & Presence of mutation & 12 & 70.59 \\
\hline Other localizations & 483 & 96.6 & Lack of mutation & 261 & 54.04 \\
\hline & & & Presence of mutation & 222 & 45.96 \\
\hline$p, \chi^{2}$ & & & 0.045 & & \\
\hline
\end{tabular}


Table II. Cont.

\begin{tabular}{|c|c|c|c|c|c|}
\hline Patient characteristics & $n$ & $\%$ & Mutation status & $n$ & $\%$ \\
\hline \multirow[t]{2}{*}{ Splenic flexure } & \multirow[t]{2}{*}{22} & \multirow[t]{2}{*}{4.4} & Lack of mutation & 17 & 77.27 \\
\hline & & & Presence of mutation & 5 & 22.73 \\
\hline \multirow[t]{2}{*}{ Other localizations } & \multirow[t]{2}{*}{478} & \multirow[t]{2}{*}{95.6} & Lack of mutation & 249 & 52.09 \\
\hline & & & Presence of mutation & 229 & 47.91 \\
\hline$p, \chi^{2}$ & & & \multicolumn{3}{|c|}{$0.0206,5.356$} \\
\hline \multirow[t]{2}{*}{ Descending colon } & \multirow[t]{2}{*}{10} & \multirow[t]{2}{*}{2} & Lack of mutation & 4 & 40.00 \\
\hline & & & Presence of mutation & 6 & 60.00 \\
\hline \multirow[t]{2}{*}{ Other localizations } & \multirow[t]{2}{*}{490} & \multirow[t]{2}{*}{98} & Lack of mutation & 262 & 53.47 \\
\hline & & & Presence of mutation & 228 & 46.53 \\
\hline$p, \chi^{2}$ & & & \multicolumn{3}{|c|}{$0.3981,0.714$} \\
\hline \multirow[t]{2}{*}{ Sigmoid colon } & \multirow[t]{2}{*}{102} & \multirow[t]{2}{*}{20.4} & Lack of mutation & 63 & 61.76 \\
\hline & & & Presence of mutation & 39 & 38.24 \\
\hline \multirow[t]{2}{*}{ Other localizations } & \multirow[t]{2}{*}{398} & \multirow[t]{2}{*}{79.6} & Lack of mutation & 203 & 51.00 \\
\hline & & & Presence of mutation & 195 & 49.00 \\
\hline \multicolumn{3}{|l|}{$p, \chi^{2}$} & \multicolumn{3}{|c|}{$0.05202,3.775$} \\
\hline \multirow[t]{2}{*}{ Rectosigmoid flexure } & \multirow[t]{2}{*}{53} & \multirow[t]{2}{*}{10.60} & Lack of mutation & 34 & 64.15 \\
\hline & & & Presence of mutation & 19 & 35.85 \\
\hline \multirow[t]{2}{*}{ Other localizations } & \multirow[t]{2}{*}{447} & \multirow[t]{2}{*}{89.4} & Lack of mutation & 232 & 51.90 \\
\hline & & & Presence of mutation & 215 & 48.10 \\
\hline$p, \chi^{2}$ & & & 0.091 & & \\
\hline Rectum & 150 & 30 & Lack of mutation & 84 & 56.00 \\
\hline & & & Presence of mutation & 66 & 44.00 \\
\hline Other localizations & 350 & 70 & Lack of mutation & 182 & 52.00 \\
\hline & & & Presence of mutation & 168 & 48.00 \\
\hline$p, \chi^{2}$ & & & 0.411 & & \\
\hline Metastases & 53 & 10.60 & Lack of mutation & 26 & 49.05 \\
\hline & & & Presence of mutation & 27 & 50.95 \\
\hline Other localizations & 447 & 89.4 & Lack of mutation & 240 & 53.69 \\
\hline & & & Presence of mutation & 207 & 46.31 \\
\hline$p, \chi^{2}$ & & & 0.522 & & \\
\hline Right side of large & 97 & 20.95 & Lack of mutation & 34 & 35.06 \\
\hline intestine & & & Presence of mutation & 63 & 64.94 \\
\hline Left side of large intestine & 366 & 79.05 & Lack of mutation & 205 & 59.25 \\
\hline & & & Presence of mutation & 141 & 40.75 \\
\hline$p, \chi^{2}$ & & & 0.00002 & 54 & \\
\hline
\end{tabular}

$B R A F$ mutations) cancers predominated in female patients with $B R A F$ mutations.

\section{Discussion}

Frequency of KRAS, NRAS and BRAF gene mutations was assessed in previous clinical trials that evaluated the efficacy of anti-EGFR antibodies in the first and third line of treatment in CRC patients [4, 11-15].

The lack of efficacy of cetuximab combined with first line chemotherapy with 5 -fluorouracil and oxaliplatin in patients with KRAS gene mutations was demonstrated in the OPUS study (the study group consisted of 314 patients). KRAS codons 12 and 13 mutations were found in $43.2 \%$ of CRC patients and the Val600Glu BRAF mutation in $3.5 \%$ of CRC patients. Efficacy of cetuximab was observed only in patients with the wild-type KRAS gene (codons 12 and 13). Rare RAS mutations were examined in archival material a few years later using the BEAMing technique. $26.3 \%$ of patients without KRAS codons 12 and 13 mutations had rare RAS mutations, including KRAS mutations in codon 59 or 61 (5.9\% of patients), in codon 117 or 146 (9.3\% of patients) as well as NRAS mutations in codon 12 or $13(6.8 \%$ of patients), in codon 59 or 61 (in $5.1 \%$ of patients) 
Table III. Relationship between occurrence of mutations in the KRAS, NRAS and BRAF genes and tumor localization in colorectal cancer (CRC) patients. * Lack of any examined mutations (wild type)

\begin{tabular}{|c|c|c|c|c|c|}
\hline Gene status & $n$ & $\%$ & Mutations & $n$ & $\%$ \\
\hline \multicolumn{6}{|l|}{ KRAS gene status: } \\
\hline \multirow{2}{*}{$\begin{array}{l}\text { Right side of large } \\
\text { intestine }\end{array}$} & \multirow[t]{2}{*}{84} & \multirow[t]{2}{*}{20.84} & Lack of mutations* & 34 & 40.48 \\
\hline & & & Presence of mutations & 50 & 59.52 \\
\hline \multirow{2}{*}{$\begin{array}{l}\text { Left side of large } \\
\text { intestine }\end{array}$} & \multirow[t]{2}{*}{319} & \multirow[t]{2}{*}{79.16} & Lack of mutations* & 205 & 64.26 \\
\hline & & & Presence of mutations & 114 & 35.74 \\
\hline$p, \chi^{2}$ & & & \multicolumn{3}{|c|}{$0.00007871,15.589$} \\
\hline \multicolumn{6}{|l|}{ NRAS gene status: } \\
\hline \multirow{2}{*}{$\begin{array}{l}\text { Right side of large } \\
\text { intestine }\end{array}$} & \multirow[t]{2}{*}{36} & \multirow[t]{2}{*}{14} & Lack of mutations* & 34 & 94.45 \\
\hline & & & Presence of mutations & 2 & 5.55 \\
\hline \multirow{2}{*}{$\begin{array}{l}\text { Left side of large } \\
\text { intestine }\end{array}$} & \multirow[t]{2}{*}{221} & \multirow[t]{2}{*}{86} & Lack of mutations* & 205 & 92.76 \\
\hline & & & Presence of mutations & 16 & 7.24 \\
\hline$p, \chi^{2}$ & & & \multicolumn{3}{|c|}{$0.7133,0.135$} \\
\hline \multicolumn{6}{|l|}{ BRAF gene status: } \\
\hline \multirow{2}{*}{$\begin{array}{l}\text { Right side of large } \\
\text { intestine }\end{array}$} & \multirow[t]{2}{*}{45} & \multirow[t]{2}{*}{17.24} & Lack of mutations* & 34 & 75.56 \\
\hline & & & Presence of mutations & 11 & 24.44 \\
\hline \multirow{2}{*}{$\begin{array}{l}\text { Left side of large } \\
\text { intestine }\end{array}$} & \multirow[t]{2}{*}{216} & \multirow[t]{2}{*}{82.76} & Lack of mutations* & 205 & 94.91 \\
\hline & & & Presence of mutations & 11 & 5.09 \\
\hline$p, \chi^{2}$ & & & 0.00 & $3,18.0$ & \\
\hline
\end{tabular}

A

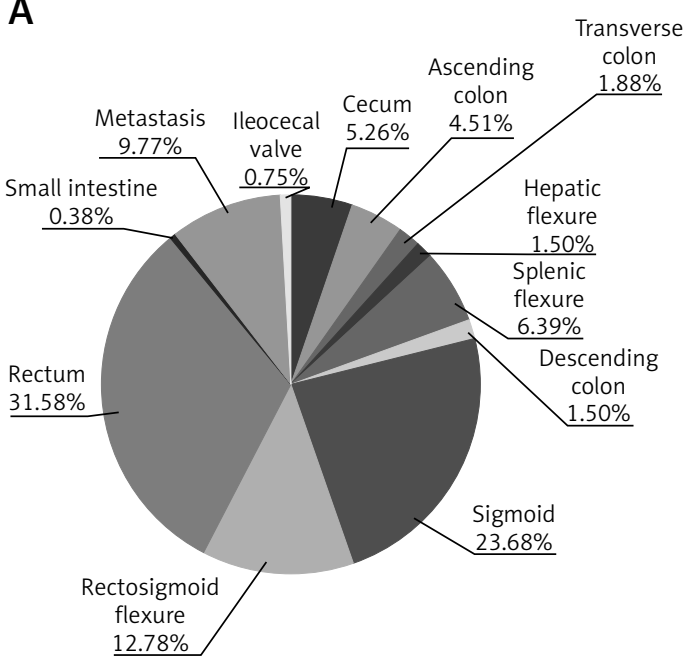

B

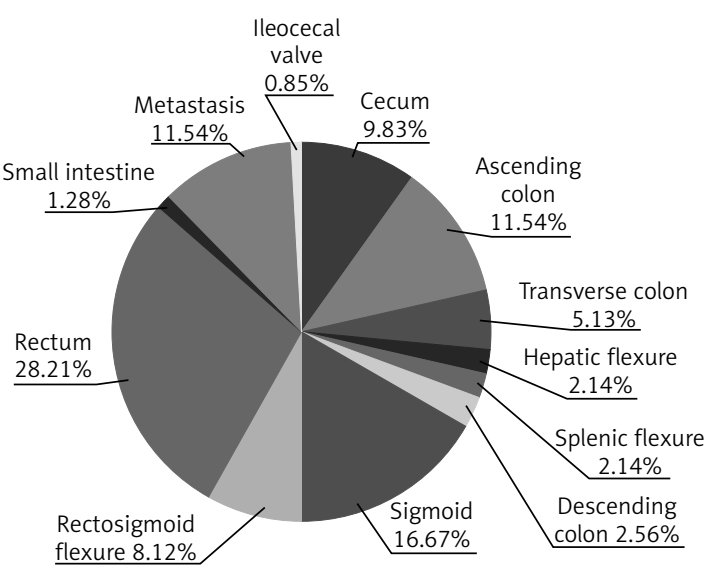

Figure 3. Differences in colorectal cancer (CRC) localization in patients without KRAS, NRAS or BRAF gene mutations (A) and in patients with mutations in the KRAS, NRAS or BRAF genes (B)

and in codon 117 or 146 (0.8\% of patients). Patients with rare $R A S$ mutations also did not benefit from cetuximab therapy $[15,16]$.

The efficacy of first line chemotherapy based on irinotecan and 5-fluorouracil with or without cetuximab in patients without KRAS mutations (codons 12 and 13) was examined in the CRYSTAL study. KRAS gene mutations in codon 12 or 13 were found in $37.3 \%$ and the Val600Glu mutation in the BRAF gene in $6.6 \%$ of CRC patients (the study group consisted of 1063 patients). The benefit of cetuximab was not the same in all patients with the wild-type KRAS gene (codons 12 and 13). Therefore, rare RAS mutations in patients enrolled in thee CRYSTAL trial were examined. $14.7 \%$ of 430 patients with wild-type KRAS codons 12 and 13 had rare RAS gene mutations. Mutations in codons 59 and 61 of the KRAS gene were present in $3.3 \%$ of patients and mutations in codons 117 and 146 were present in $5.6 \%$ of patients. NRAS gene mutations were found in codons 12 and 13 in 3.5\% of patients, in codons 59 and 61 in $2.8 \%$ of patients, and in codons 117 and 146 in $0.9 \%$ of patients. Effectiveness of cetuximab in patients with rare $R A S$ mutations was unsatisfactory $[9,17]$. 
The PRIME clinical trial compared the efficacy and safety of panitumumab, 5-fluorouracil and oxaliplatin with chemotherapy alone in the first-line treatment of 1096 CRC patients. $67 \%$ of patients had KRAS codon 12 or 13 mutations. KRAS codon 61 was mutated in $4 \%$ of patients and codon 117 or 146 was mutated in $6 \%$ of patients. Mutations in the NRAS gene in codons 12 and 13 were found in $3 \%$ of patients and in codon 61 in $4 \%$ of patients. There were no mutations in codon 117 or 146 of the NRAS gene. Mutations in the BRAF gene occurred in $8 \%$ of CRC patients. The effectiveness of panitumumab was closely related to the absence of mutations in RAS and BRAF genes [8].

In the PEAK study (221 patients with known status of examined genes), the effectiveness of panitumumab monotherapy in third line treatment of CRC patients was examined. The following mutations were found in CRC patients from the PEAK trial: in codon 12 or 13 of the KRAS gene in $43.1 \%$ of patients, in codon 59 or 61 of the KRAS gene in $4.8 \%$ of patients, in codon 117 or 146 of the KRAS gene in $5 \%$ of patients, in codon 12 or 13 of the NRAS gene in $4.2 \%$ of patients, in codon 59 or 61 of the NRAS gene in $3 \%$ of patients and in codons 117 and 146 of the NRAS gene in $1.1 \%$ of patients. The occurrence of the mutations was closely related to the lack of efficacy of panitumumab [18].

The incidence of examined mutations in our patients is lower than in the cited studies. Mainly, the frequency of mutations in the KRAS and $B R A F$ genes is lower than in the CRYSTAL and PRIME studies. This is probably due to the lower sensitivity of real-time PCR technique used in the routine diagnosis of RAS and BRAF mutations in CRC patients in our study. The results of our study indicated that the most frequent mutation in the KRAS gene was Gly12Asp and in the BRAF gene was Val600Glu, according to the results of genetic tests carried out in clinical trials. Mutation in codon 61 was the most frequent mutation in the NRAS gene in our patients, which does not match with the results of other studies. The research should be supplemented by demonstrating that tumor heterogeneity and/or low sensitivity of diagnostic tests may have contributed to the fact that patients with wild-type RAS did not respond to anti-EGFR therapy due to the presence of mutations. The weakness of our study was the lack of information on how the patients were treated.

Kodaz et al. studied the relationship between the prevalence of KRAS mutations and the clinicopathological characteristics of colorectal cancer. The study group included 189 patients with CRC diagnosis. $47.6 \%$ of patients had a mutation in the KRAS gene. The study also showed that the most common KRAS mutations occurred in codon $12(73.3 \%$ of all $K R A S$ examined mutations) and the most common substitution was Gly12Asp (42.4\% of all KRAS ex- amined mutations). The authors found that a high percentage of young CRC patients ( $<40$ years) had the wild-type KRAS gene. They also suggested that KRAS point mutations in colorectal cancer exhibited a heterogeneous distribution in terms of tumor localization. In the cited study, there was no significant difference in KRAS mutation frequency according to tumor localization. Moreover, the authors found no association between KRAS mutation occurrence and gender [19].

Kawazoe et al. searched for KRAS, NRAS, BRAF and PIK3CA gene mutations in the material from 246 patients with metastatic CRC. Fifty percent of patients had wild-type examined genes. Mutations in codons 12 and 13 of KRAS gene were found in $34.1 \%$ of patients, while mutations in codons 61 and 146 were detected in 10 cases (3.8\%). NRAS gene mutations occurred in 11 patients (4.2\%) and Val600Glu mutation in the BRAF gene occurred in 14 (5.4\%) people. The authors stated that primary rectal tumors tended to be more frequently RAS-mutated and BRAF mutant tumors were more likely to develop in the right colon. They observed no significant association between RAS gene status and other clinicopathological features such as age, sex, primary lesion localization, histology, or site of metastases, which is similar to the results of the study by Morris et al. [20, 21].

In our results, mutations were found to be associated with sex and anatomical location of the tumor. We observed the highest percentage of tumors with KRAS, NRAS and BRAF gene mutations in colon cancers. Moreover, the highest percentage of tumors with mutations were found in the right side of the large intestine. A higher percentage of female patients had KRAS, NRAS or BRAF mutations than male patients, which was also observed by $\mathrm{Ng}$ et al. in their research [22].

KRAS mutations were reported to be more frequent in right colon tumors by Bleeker et al. [23] and Loree et al. [24], but in left colon tumors by Zulhabri et al. [25]. Watanabe et al. [26] and Sinicrope et al. [27] found that KRAS codon 12 or 13 mutations were significantly more frequent in the right colon. Yamauchi et al. [28] reported that KRAS mutations were more common in cecum tumors. Brink et al. [29] reported that KRAS codon 13 mutation was more common among females with rectal tumors.

Moretto et al. [11] conducted a study of 75 CRC patients with wild-type RAS and BRAF genes. They found that patients with tumors located on the right side of the large intestine more often did not respond to therapy based on cetuximab or panitumumab compared to patients with tumors on the left side of the large intestine. If we assume that mutations occur more often on the right side of the large intestine, this relationship may re- 
sult from the problems with detection of RAS and $B R A F$ gene mutations due to tumor heterogeneity or low sensitivity of molecular tests.

In conclusion, our study showed that the occurrence of mutations in the KRAS, NRAS and BRAF genes is not accidental and depends on the location of CRC tumors. In case of failure of treatment with anti-EGFR antibodies in patients with tumor localization suggesting a higher probability of mutation presence, an insightful molecular examination is necessary.

\section{Availability of data and materials}

7409c6

https://figshare.com/s/c7de96cf9b0220-

https://figshare.com/s/c6824d9cef9bbfb2272e

\section{Conflict of interest}

The authors declare no conflict of interest.

\section{References}

1. American Cancer Society. Colorectal cancer facts and figures 2017-2019. American Cancer Society, Atlanta 2017.

2. Colussi D, Brandi G, Bazzoli F, Ricciardiello L. Molecular pathways involved in colorectal cancer: implications for disease behavior and prevention. Int J Mol Sci 2013; 14: 16365-85.

3. Lamami Y, Mesediyeva R, Arikan S, et al. Preliminary report: one of the PD-1 gene variants may be a valuable marker for colorectal cancer. Arch Med Sci 2018; 3: e34-e40.

4. Lovly C, Horn L, Pao W. KRAS. My Cancer Genome. https://www.mycancergenome.org/content/disease/ colorectal-cancer/kras/?tab=0, 2015 (accessed: 7 December 2017).

5. Kim SE, Paik HY, Yoon H, Lee JE, Kim N, Sung MK. Sexand gender-specific disparities in colorectal cancer risk. World J Gastroenterol 2015; 21: 5167-75.

6. https://www.accessdata.fda.gov/drugsatfda_docs/label/2012/125084s0228lbl.pdf/ (accessed: 22 February 2018).

7. https://www.accessdata.fda.gov/drugsatfda docs/label/2009/125147s080lbl.pdf/ (accessed: 22 February 2018).

8. Douillard JY, Siena S, Cassidy J, et al. Randomized, phase III trial of panitumumab with infusional fluorouracil, leucovorin, and oxaliplatin (FOLFOX4) versus FOLFOX4 alone as first-line treatment in patients with previously untreated metastatic colorectal cancer: the PRIME study. J Clin Oncol 2010; 28: 4697-705.

9. Van Cutsem E, Köhne CH, Láng I, et al. Cetuximab plus irinotecan, fluorouracil, and leucovorin as first-line treatment for metastatic colorectal cancer: updated analysis of overall survival according to tumor KRAS and BRAF mutation status. J Clin Oncol 2011; 29: 2011-9.

10. Benson $A B$, Venook AP, Cederquist L, et al. Colon cancer. Version 1.2017. J Natl Compr Canc Netw 2017; 15: 370-98.

11. Moretto R, Cremolini C, Rossini D, Pietrantonio F, Battaglin F. Location of primary tumor and benefit from anti-epidermal growth factor receptor monoclonal antibodies in patients with RAS and BRAF wild-type metastatic colorectal cancer. Oncologist 2016; 21: 988-994.

12. Pang XL, Li QX, Ma ZP, et al. Association between clinicopathological features and survival in patients with primary and paired metastatic colorectal cancer and KRAS mutation. Onco Targets Ther 2017; 10: 2645-54.

13. Li W, Qiu T, Ling Y, Guo L, Li L, Ying J. Molecular pathological epidemiology of colorectal cancer in Chinese patients with KRAS and BRAF mutations. Oncotarget 2015; 37: 39607-13.

14. Irahara N, Baba Y, Nosho K, et al. NRAS mutations are rare in colorectal cancer. Diagn Mol Pathol 2010; 19: 157-63.

15. Bokemeyer C, Bondarenko I, Hartmann JT, et al. Efficacy according to biomarker status of cetuximab plus FOLFOX-4 as first-line treatment for metastatic colorectal cancer: the OPUS study. Ann Oncol 2011; 22: 1535-46.

16. Bokemeyer C, Köhne CH, Ciardiello F, et al. FOLFOX4 plus cetuximab treatment and RAS mutations in colorectal cancer. Eur J Cancer 2015; 51: 1243-52.

17. Van Cutsem E, Lenz HJ, Köhne CH, et al. Fluorouracil, leucovorin, and irinotecan plus cetuximab treatment and RAS mutations in colorectal cancer. J Clin Oncol 2015; 33: 692-700.

18. Patterson SD, Peeters M, Siena S, et al. Comprehensive analysis of KRAS and NRAS mutations as predictive biomarkers for single agent panitumumab (pmab) response in a randomized, phase III metastatic colorectal cancer (mCRC) study (20020408). J Clin Oncol 2013; 31: 3617.

19. Kodaz H, Hacibekiroblu I, Erdogan B, et al. Association between specific KRAS mutations and the clinicopathological characteristics of colorectal tumors. Mol Clin Oncol 2015; 3: 179-84.

20. Kawazoe A, Shitara K, Fukuoka S, et al. A retrospective observational study of clinicopathological features of KRAS, NRAS, BRAF and PIK3CA mutations in Japanese patients with metastatic colorectal cancer. BMC Cancer 2015; 15: 258.

21. Morris VK, San Lucas FA, Overman MJ, et al. Clinicopathologic characteristics and gene expression analyses of non-KRAS 12/13, RAS-mutated metastatic colorectal cancer. Ann Oncol 2014; 25: 2008-14.

22. Yan-Seen Ng J, Lu CT, King-Yin Lam A. BRAF mutation: Current and future clinical. Histol Histopathol 2019; 34: 469-77.

23. Bleeker WA, Hayes VM, Karrenbeld A, et al. Impact of KRAS and TP53 mutations on survival in patients with left- and right-sided Dukes' C colon cancer. Am J Gastroenterol 2000; 95: 2953-7.

24. Loree JM, Pereira A, Lam M, et al. Classifying colorectal cancer by tumor location rather than sidedness highlights a continuum in mutation profiles and consensus molecular subtypes. Clin Cancer Res 2017; 24: 1-11.

25. Zulhabri O, Rahman J, Ismail S, Isa MR, Wan Zurinah WN. Predominance of $\mathrm{G}$ to $\mathrm{A}$ codon 12 mutation $\mathrm{K}$-ras gene in Dukes' B colorectal cancer. Singapore Med J 2012; 53: 26-31.

26. Watanabe $\mathrm{T}$, Yoshino $\mathrm{T}$, Uetake $\mathrm{H}$, et al. KRAS mutational status in Japanese patients with colorectal cancer: results from a nationwide, multicentre, cross-sectional study. Jpn J Clin Oncol 2013; 43: 706-12.

27. Sinicrope FA, Mahoney MR, Yoon HH, et al. Analysis of molecular markers by anatomic tumor site in stage III colon carcinomas from adjuvant chemotherapy Trial NCCTG N0147 (Alliance). Clin Cancer Res 2015; 21: 5294-304. 
28. Yamauchi M, Morikawa T, Kuchiba A, et al. Assessment of colorectal cancer molecular features along bowel subsites challenges the conception of distinct dichotomy of proximal versus distal colorectum. Gut 2012; 61: 847-54.

29. Brink M, de Goeij AF, Weijenberg MP, et al. K-ras oncogene mutations in sporadic colorectal cancer in The Netherlands Cohort Study. Carcinogenesis 2003; 24: 703-10. 